\title{
Lingua plicata
}

\section{Lluís Nisa MD, Roland Giger MD}

$\mathrm{A}$ 30-year-old woman who was a nonsmoker received chemotherapy and radiotherapy for Hodgkin lymphoma. Six months after the end of treatment, she was doing well with no evidence of persisting lymphoma. The patient was referred to our clinic by her oncologist for evaluation of the irregular appearance of her tongue (Figure 1). This condition had developed over the previous few months, and the patient was concerned about halitosis and the appearance of her tongue. She was also experiencing mild xerostomia that had begun after radiotherapy. We diagnosed lingua plicata and advised the patient to brush her tongue regularly. After three months, her halitosis had resolved, although the irregular appearance of the tongue remained.

Lingua plicata is a benign disorder and is frequently found in healthy people. Also known as fissured tongue, scrotal tongue or plicated tongue, it is characterized by the development of deep grooves or fissures on the dorsal and lateral surfaces of the tongue. Lingua plicata is common in older people and has an estimated prevalence of up to $20 \%$ in the general population. ${ }^{1}$ This condition is often associated with geographic tongue, and it is more common in people with Down syndrome, Melkersson-Rosenthal syndrome, psoriasis, Sjögren syndrome and chronic granulomatous disease. ${ }^{2,3}$ Lingua plicata was probably a coincidental finding in our patient because there is no established relation between this condition and Hodgkin lymphoma or its treatments. Our patient's radiotherapy-induced xerostomia probably worsened her halitosis, which prompted her to consult our clinic.

Lingua plicata is usually asymptomatic and discovered incidentally, but the accumulation of food in the fissures can lead to halitosis and focal glossitis. The lesions may improve spontaneously, but good oral hygiene with gentle brushing of the tongue can reduce complications. Other general measures include avoiding tobacco, alcohol and foods that irretate the mucosa of the tongue. ${ }^{2}$

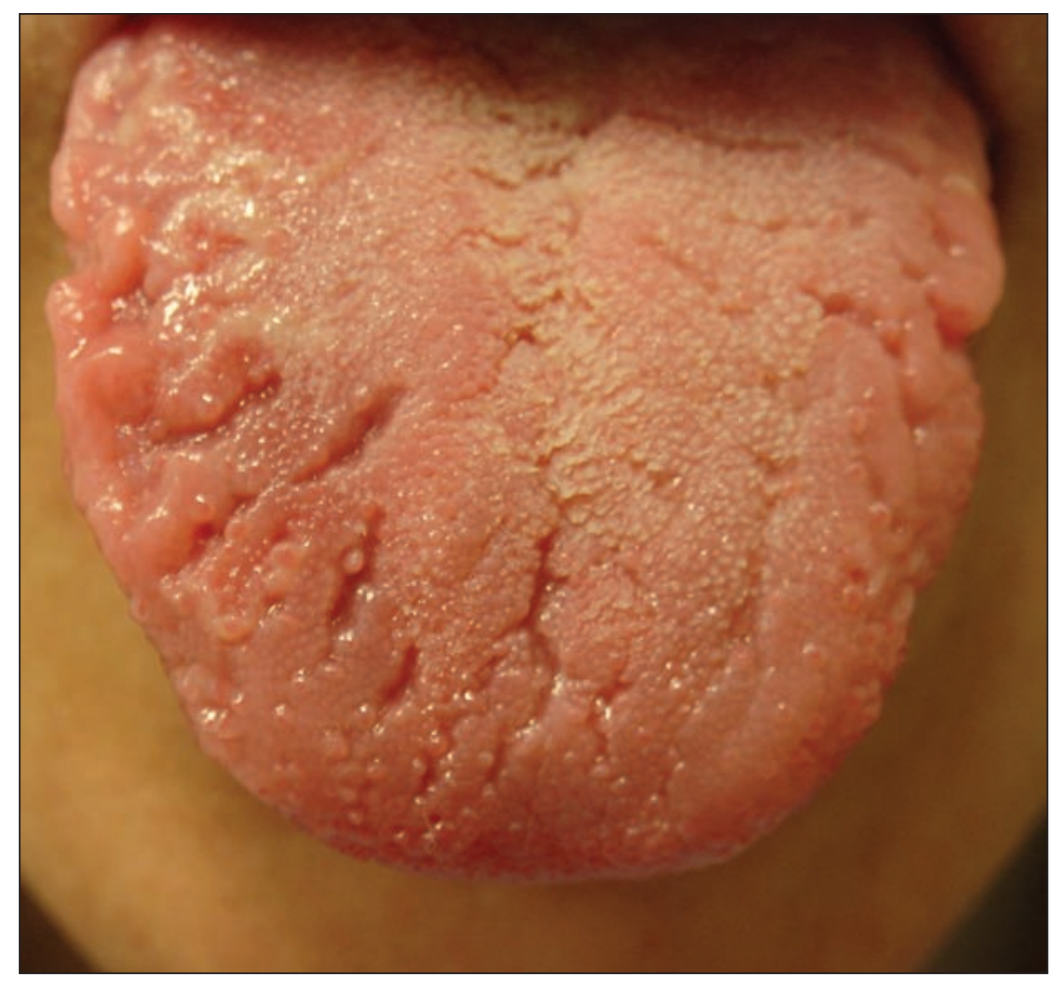

Figure 1: Lingua plicata is characterized by deep grooves on the tongue's dorsum and sides, as seen in a 30-year-old woman following treatment for Hodgkin lymphoma.

\section{References}

1. Avcu N, Kanli A. The prevalence of tongue lesions in 5150 Turkish dental outpatients. Oral Dis 2003;9:188-95.

2. Reamy BV, Derby R, Blunt CW. Common tongue conditions in primary care. Am Fam Physician 2010;81:627-34

3. Kaminagakura E, Jorge J Jr. Melkersson Rosenthal syndrome: a histopathologic mystery and dermatologic challenge. J Cutan Pathol 2011;38:241-5.

Clinical images are chosen because they are particularly intriguing, classic or dramatic. Submissions of clear, appropriately labelled high-resolution images must be accompanied by a figure caption and the patient's written consent for publication. A brief explanation (250 words maximum) of the educational significance of the images with minimal references is required.
This article has been peer reviewed.

Affiliation: From the Department of Otolaryngology, Head and Neck Surgery, Hôpital de Sion, Sion, Switzerland.

Correspondence to: Dr. Lluís Nisa, 1lnisa@yahoo.ca

CMAJ 2012. DOI:10.1503 /cmaj.111255 